\title{
Effective Factors in Causing Leakage in Water Supply Systems and Urban Water Distribution Networks
}

\author{
Hassan Saghi", Abbas Ansari Aval \\ Department of Civil Engineering, Hakim Sabzevari University, Sabzevar, Iran \\ Email address: \\ h.saghi@hsu.ac.ir (H. Saghi), aaabas1192@gmail.com (A. A. Aval)
}

\section{To cite this article:}

Hassan Saghi, Abbas Ansari Aval. Effective Factors in Causing Leakage in Water Supply Systems and Urban Water Distribution Networks. American Journal of Civil Engineering. Special Issue: Research and Practices of Civil Engineering in Developing Countries. Vol. 3, No. 2-2, 2015, pp. 60-63. doi: 10.11648/j.ajce.s.2015030202.22

\begin{abstract}
Water has a vital role in the country's economic development, since most part of it is dry and desert. Whereas, water has been cheap and easy accessing, the authorities of the urban water distribution organizations have not paid so much attention to the decreasing of the unaccounted for water (U.F.W) as a solution for saving water, the decreasing of the cost of preparing water and the increasing of their efficiency or income. In recent years, the U.F.W has been paid attention because of the shortage of resources and the cost increasing of water preparation. Therefore, along with preparing water from new resources, the water wasting in different stages of transmission, refinement and distribution of water should be prevented as a long term programing. In this article, the effective elements in causing leak have been explained. The results show that the most leakage of water deals with the parameters such as pressure, quality, diameter and age of the pipes.
\end{abstract}

Keywords: Economic Development, Urban Water Distribution, Water Leakage

\section{Introduction}

In recent years, the international communities and the dveloped countries have paid a special attention to the shortage of the water resources and finding new solutions for it, especially to prevent water wasting. The U.F.W and leakage in the water supply system and the urban water distribution networks have been paid attention in many countries. In recent three decades good experiences in theoretical and executions in decreasing of the water leakage have been obtained through the scientific and systematic planning. Fortunately, in Iran, this subject has been dealt with for more than one decade. The first step was preparing a national development plan for upgrading the urban water distribution in the second development plan of the country. The second step has been done by controlling offices of the U.F.W in the water and waste companies of the country in which the study of decreasing the water wasting has been paid.

The unaccounted water has many privileges; some of them are mentioned here:

- Decreasing the investment cost of the constructing of the installations for water resources and the development of water supply system

- Decreasing the entering of the pollution through the leak points

- Increasing the efficiency of the water and waste companies in technical engineering, performance and subscription sections

- Increasing the income of the water and waste company.

- Obtaining the consent of the subscribers.

Decreasing the loss of water in water supply system network involves knowing the amount of loss, causes, methods and priority of these factors. The next stage includes the location detection and determining the position of the most hazardous leakage points and the repairing and rebuilding the network.

\section{The Effective Factors in Causing Leak}

The accidents which happen in the water supply system networks are usually high. For instance, about one million accidents have happened in water supply system networks in the country in 1998 . This damage costs about $20 \%$ of the total income of the Water and Waste Company. This cost has been for repairing, rebuilding and improving of the network. Over $30 \%$ of these accidents have happened on the pipelines of the water supply system networks. Many factors are involved in the leakage detection of the water in the network. 
Some of these effective factors will be paid to in this article.

\subsection{The Material of the Pipes}

One of the effective factors in water leakage is the material of the pipes. An experiment on the pipes in Chaloos showed that the asbestos pipes have the least ruins and the galvanized pipes have the most efficiency [1]. This is shown in Fig. 1. The experience showed that in leakage detection methods, the material of the pipes has been one of the most important parameters in the causing leakage in the networks. The results of the studies, which have been done by Jing and Zhi-Hong, showed that the material of the pipes is the most important factor in causing leaks. Among different materials of pipes, iron pipes have the most leakage accidents and asbestos pipes have the least.

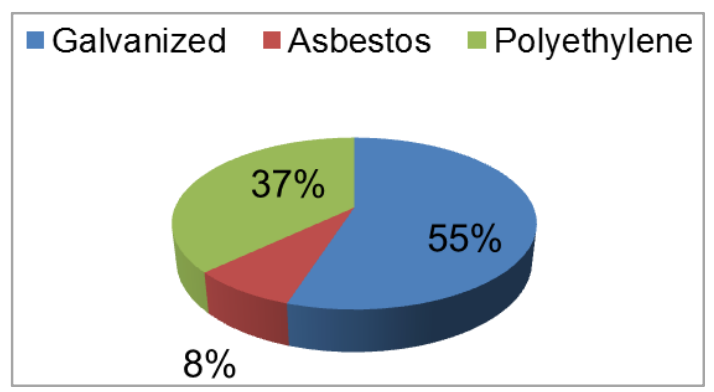

Fig. 1. Accidents percentages for various materials of pipes [1].

\subsection{The Age of the Pipes}

The age of pipes has a direct or indirect effect on the amount of leakage. So a program can be planned with a time table for the efficiency and rebuilding of the pipes with different qualities, so that the loss of water will decrease. On the basis of the experiments, which have been done in Chaloos, the suggested time for galvanized pipe is 15 years and for polyethylene is about 16 years [1]. The studies of recent years show that with the increasing of the pipes age, the loss can reach to $50 \%$ of the entered water into the networks [2].

\subsection{The Diameter of the Pipes}

The diameter of the pipes is one the effective element in the rate of the accidents and the loss. The hydraulic pressure decreases when the diameter increases, so the loss comes down. Although, using high diameter pipes involves more cost, this investment seems to decrease the loss of leaking water in a long range program.

The more diameter of the pipe, the thicker of the shell the pipe has. So the resistance of the pipe increases against the outside or inside pressure and the destructive elements of the environment. For instance, on the basis of a research, which has been done in Netherlands, in every $100 \mathrm{Km}$ with $150 \mathrm{~mm}$ pipe diameter, 25 cracks are expected annually [3].

\subsection{The Pressure}

Another hydraulic parameter, which determines the performance condition and the servicing of urban water supply system network, is pressure with a high importance. High pressure causes the increasing of leak, and the loss of consuming water and the number of the accidents in the network. On the other hand, low pressure in the network causes the inability of complete supplying water or result in providing unsuitable water. The pressure also is effective on the stability and the structure of the system. With high pressure, the probability of the accidents and the crack of the system increase and the stability performance and suitable servicing of the network endangered. If the changing of the pressure happens according to the prescribed standards, it will be appropriate for a network user. So that the different aims of the network which are usually contradictory on the basis of the pressure reaches to a balance. Therefore, knowing the conditions of the changing pressure has a high importance. The loss is sometimes because of the network pressure conditions. In other words, the cracks open with the high pressure and close with the low pressure. The amount of loss in a point has a direct relation with the amount of pressure on that point so the amount of loss changes according to the changes in pressure.

The pressure parameter is the most important one among the different parameters; this element is paid attention so much in the new methods of leakage detection.

\subsection{The Movement of the Soil Around the Pipe}

The movement of the soil may happen because of sliding of the ground or shaking of the earthquake. This movement brings a lot of pressure on the pipe and can cause cracks in the pipe, gaps in the joints or the breaking of the pipes.

\subsection{The Movement of the Soil Around the Pipe}

The corrosion of the environmental soil and water for all of the metal structures is inevitable (especially about the buried pipes and joints). This corrosion in the motor pumps pipes and taps can happen through cavitation or chemical corrosion of the water supply system pipes make corrosion by water from inside and solid from outside. Both of them happen due to the existence of unsuitable components and salts in water and soil. This corrosion happens through the forming the galvanic cells or concentration cells, so that a part of the pipe takes the role of anode and other part of pipe the role of cathode. So the currency of the metal happens from anode to cathode therefore the metals which has anode role is ruined.

The iron or steel pipes have been used in the water supply system networks for more than five centuries. The corrosion usually happens over time. The corrosion of the pipes has an important role in the quality of the water. Some of the corrosions of the pipes are as follow [4]:

- The water takes color, smell and taste.

- It prepares a good background for the growth of microbes.

- It attracts and gathers the arsenic materials

\subsection{Hit}

Most part of the water supply system network goes under 
the streets of the cities. In the cases of digging by the other organizations such as gas, electricity, communication and may damage the pipes.

\subsection{Using Unsuitable Materials for the Basis and Coverage of the Pipes}

While installing the pipes, the surrounding of them should be made so that a good basis is prepared for the setting of the pipes and the extra tensions does not transmit to the pipes. If unsuitable materials (such as big seed materials or those that their summit is remarkable) are used, unbalance pressures are applied to the pipes and damage them.

\subsection{Incorrect Installation}

Installation by unprofessional workers or using incorrect and non-standardized techniques may result in incomplete sealing of the joints. In this case there are some leaks in the joints from the beginning and this would increase over time.

\subsection{Water Hammer Hit}

When water is pumped directly into the water supply system network a water hammer hit may cause accidents and breaks the pipes and joints. Wherever the pipe is weak because of corrosion this hit becomes stronger. This hit makes some quicks waves and passes away fast, so it may cause different dangers and damages in the pipelines.

Generally, this water hammer hit in the pipeline projects has an important role and ignoring it results in very large damages in the equipment. In order to analyze the water hammer hit, many types of software, on the basis of different mathematical methods and digits are provided. Three software, Hytran, AFT impulse and Hammer are used for analyzing the water hammer hit in the pipeline network. The outputs of AFT impulse were the most realistic and Hammer's result was far from the reality and expectations. It was showed through Hammer's program that in spite of the installation of the controlling devices to decrease the minimal pressure, not only the minimal pressure did not change but the maximal pressure increased. But AFT impulse and Hytran had a good compiling with each other and with the practical results.

Other performances against water hammer hit were done by Daneshfaraz and Moradi [5]. They used a tank of air with $3 \mathrm{~m} 3$ capacity with an air compressor and a one-way tap in a pump station. They also put an air tap and an empty tap along the pipeline, with using protection equipment, they succeeded to minimize the positive pressure and to omit the negative pressure [5].

\subsection{Clogging the Components Joints and Pipes}

Clogging happens when some sediment and objectives enter into the pipes and their components. This makes a condition in which the weak parts break.

\subsection{The Effect of Temperature}

When the temperature is high, the resistance of the pipes, especially the pipes with artificial material such as plastic, polyethylene components, comes down very much. When the depth is not suitable or the coverage is not enough, the low temperature causes freezing. This freezing makes some tension inside the pipes.

\subsection{The Depth of Placement of the Pipes}

The depth of placement of pipes in the ground can have a role in leaking. The studies which have been done by Jing and $\mathrm{Zi}$-Hong showed that the depth of placement has an effect on leaking. But the results show that other factors such as the material and the diameter of pipe and the pressure have more importance [6].

\subsection{The Pressure of the Cars on the Surface of Roads and Ground}

Another factor of leaking is the pressure of the passing cars on road and ground where the pipeline buried. Although in new methods of leakage detections, this factor mostly is not considered, the studies which were done by lee and his colleagues mention that this factor has a special importance. This parameter should be considered in the future studies [7].

\subsection{Corrosive Waters}

The corrosive waters cause corrosion and weaken the pipes. Corrosion happens with tiny holes and developed over time.

\subsection{The Movement of Soil}

The clay soil contracts or expands according to its moisture. The resulted movement may cause loosing of the joints and local cracks on the pipelines.

\subsection{The Damages to the Pipes by the Other Service Organizations}

The performances which are done by other service organizations such as gas and electricity may cause some leakages, unsuitable joints and non-standard piping.

\subsection{Poor Quality Connections and Nonstandard Plumbing}

The loss of water is usually very much when unsuitable joints are used or incorrect piping is performed. Controlling these materials and performances can prevent loss of water, remarkably.

\subsection{The Summit of Ground}

So much using of the underground water in some areas causes the ground summit in which the pipe may crack and leak.

\subsection{Climate Conditions}

The climate conditions of the area which compose of the maximum and minimum air temperature, the quality of soil, raining, freezing and so on, have a remarkable effect on the 
breaking of the pipe.

\section{The Priority of Effective Factors in Causing Leakage}

The priority of the factors is needed in this stage. Some new methods of leakage detection through all over the world and the parameters which are effective in causing leakage are referred in the table 1 .

Table 1. Main parameters considered for leakage.

\begin{tabular}{|c|c|c|}
\hline Researcher & Reference & $\begin{array}{l}\text { Main pipe parameters considered } \\
\text { in causing leakage }\end{array}$ \\
\hline Jing and Zhi-Hong & {$[6]$} & $\begin{array}{l}\text { Material, age, pressure, diameter, the } \\
\text { depth of the placement of the pipe }\end{array}$ \\
\hline Li et al. & [7] & Material, age, pressure, diameter \\
\hline Perez et al. & [8] & pressure \\
\hline Marunga et al. & [9] & pressure \\
\hline Nicolini et al. & [10] & pressure \\
\hline Berardi et al. & {$[11]$} & Age, diameter, length \\
\hline Araujo et al. & [12] & pressure \\
\hline
\end{tabular}

\section{Discussion and Conclusion}

As presented earlier, numerous factors have effective role in causing leakage. However, considering all of them is almost impossible in different methods of leak detections. Therefore, with considering some of the important factors, it is tried to do leak detection in the water supply network. With considering these methods, it can be easily found that the pressure, age, material and diameter of the pipe are taken as the main factors and other factors can be ignored. As shown in table 1, among the four parameters including material, age, diameter and pressure of the pipe, the pressure element is the most important one. This element is considered in the most methods of leakage detection. Therefore, studying more about this parameter can result in holistic view, collectivity and designing a more efficient water supply system network.

\section{References}

[1] Tabesh, M., Karimi, K. "Determination of the leak detection and the renewal time of urban water by analyzing the accident data," No. 5, pages 597 to $610,2006$.
[2] M. Schouten, and R. D. Halim, "Resolving strategy paradoxes of water loss reduction: A synthesis in Jakarta." J. Resources, Conservation and Recycling, vol. 54, pp. 1322-1330, 2010.

[3] Tabesh, M. Honari, H.r. "Analysis of accidents in the urban water distribution networks", water and environment magazine, NO. 50, pages 17-23, 2002.

[4] V. Chawla, P. G. Gurbuxani, and G. R. Bhagure, "Corrosion of Water Pipe: a Comprehensive Study of Deposits." J. Minerals and Materials Characterization and Engineering, PP. 479-492, 2012.

[5] Danshfraz, R., Moradi, N. "Evaluation of water hammer in pumping station and water pipeline using software AFT-Impulse", accepted at the first conference on Kerman water and sanitation, 2012.

[6] K. Jing, and Z. Zhi-Hong, "Time Prediction Model for Pipeline Leakage Based on Grey Relational Analysis." J. Physics Procedia, vol. 25, pp. 2019-2024, 2012.

[7] W. Li, W. Ling, S. Liu, J. Zhao, R. Liu, Q.Chen, Z. Qiang, and J $\mathrm{Qu}$, "Development of system for detection, early warning, and control of pipeline leakage in drinking water distribution: A case study." J. Environmental Science, vol. 23(11), pp. 1816-1822, 2011.

[8] R. Perez, V. Puig, J. Pascual, J. Quevedo, E. Landeros, and A. Peralta, "Methodology for leakage isolation using pressure sensitivity analysis in water distribution networks.” J. Control Engineering Practice, vol. 19, pp. 1157-1167, 2011.

[9] A. Marunga, Z., Hoko, and E. Kaseke, "Pressure management as a leakage reduction and water demand management tool: The case of the City of Mutare, Zimbabwe." J. Physics and Chemistry of the Earth, vol. 31, pp. 763-770, 2006.

[10] M. Nicolini, C. Giacomello, and K. Ded, "Calibration and Optimal Leakage Management for a Real Water Distribution Network." J. Water Resources Planning and Management, pp. 134-142, 2011.

[11] L. Berardi, O., Giustolisi, and F. Primativo, "Exploiting multi-objective strategies for optimal rehabilitation planning." In Proceedings of Computer and Control in Water Industry (CCWI) - Water Management ChallengesinGlobal Changes-Ulaniki, Taylor and Francis Group, London, PP. 23-30, 2007.

[12] L. S. Araujo, H. Ramos, S. T. Coelho, "Pressure Control for Leakage Minimization in Water Distribution Systems Management.” J. Water Resources Management, VOL. 20, pp. 133-149, 2006. 